\title{
Dermoscopy of Nevus Lipomatosus Cutaneous Superficialis in a patient with Skin Type IV
}

\author{
Boina Kinnera ${ }^{1}$, Sreeramu Suggu ${ }^{1}$, Venkatachalam Konakanchi ${ }^{1}$
}

1 Department of DVL, Andhra medical college, Visakhapatnam, Andhra Pradesh, India

Key words: Dermoscopy, NLCS, cerebriform appearance, Indian skin

Citation: Kinnera B, Suggu S, Konakanchi V. Dermoscopy of nevus lipomatosus cutaneous superficialis in a patient with skin type IV. Dermatol Pract Concept. 2022;12(1):e2022001. DOI: https://doi.org/10.5826/dpc.1201a01

Accepted: April 8, 2021; Published: January, 2022

Copyright: $@ 2022$ Kinnera et al. This is an open-access article distributed under the terms of the Creative Commons

Attribution-NonCommercial License (BY-NC-4.0), https://creativecommons.org/licenses/by-nc/4.0/, which permits unrestricted noncommercial use, distribution, and reproduction in any medium, provided the original authors and source are credited.

Funding: None.

Competing interests: None.

Authorship: All authors have contributed significantly to this publication.

Corresponding author: Dr. Konakanchi Venkatachalam, Department of DVL, Andhra medical college, Visakhapatnam, Andhra Pradesh, India. Email: drkvchelam99@gmail.com

\section{Introduction}

Nevus lipomatosus cutaneous superficialis (NLCS) is a hamartomatous condition characterized by the presence of mature lipocytes in the dermal tissue [1]. Very few case reports had been published on the dermoscopic appearance of NLCS. We, herein, describe the dermoscopic appearance of NLCS in the skin of an Indian man.

\section{Case Presentation}

A 32-year-old man with skin type IV presented with a 1-year history of a slowly growing painless swelling, which consisted of papules grouped into a papillomatous plaque over the left side of his lower back (Figure 1). Dermoscopic examination was done using a DermLite DL4 dermatoscope $(\times 10)$ with polarized mode and pigment-enhancing mode. It showed a cerebriform pattern with sulci and gyri, multiple yellow-colored structureless areas, white structureless areas, meshwork-like pigmented lines, where a few lines were seen as 2 parallel lines, keratotic plugs in the sulci, and a rim

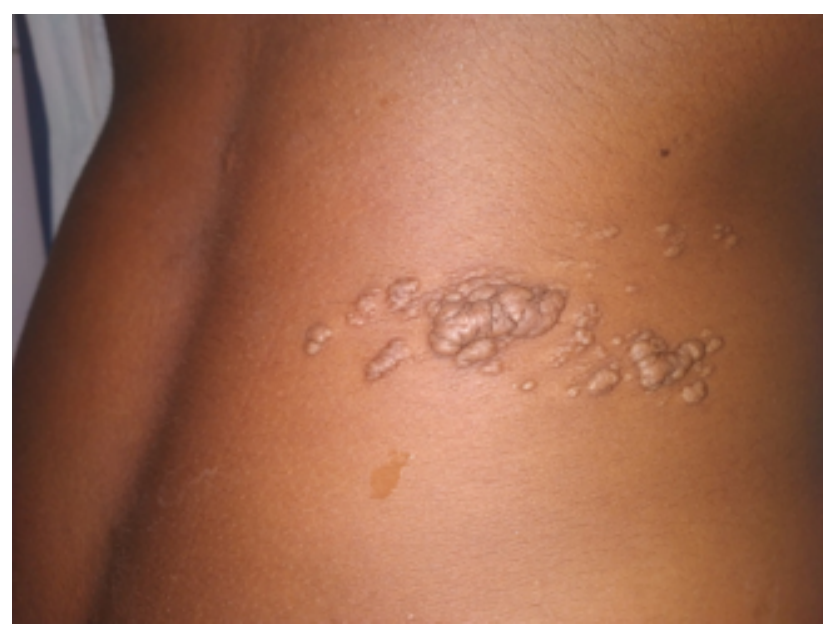

Figure 1. Skin-colored papules forming a plaque over the left lumbar area.

of white homogenous area at the periphery (Figure 2A). The prominence of yellowish structures around hair follicles was not noted in this case, as has been described in literature on similar phototype. The pigment-enhancing mode on dermoscopy 


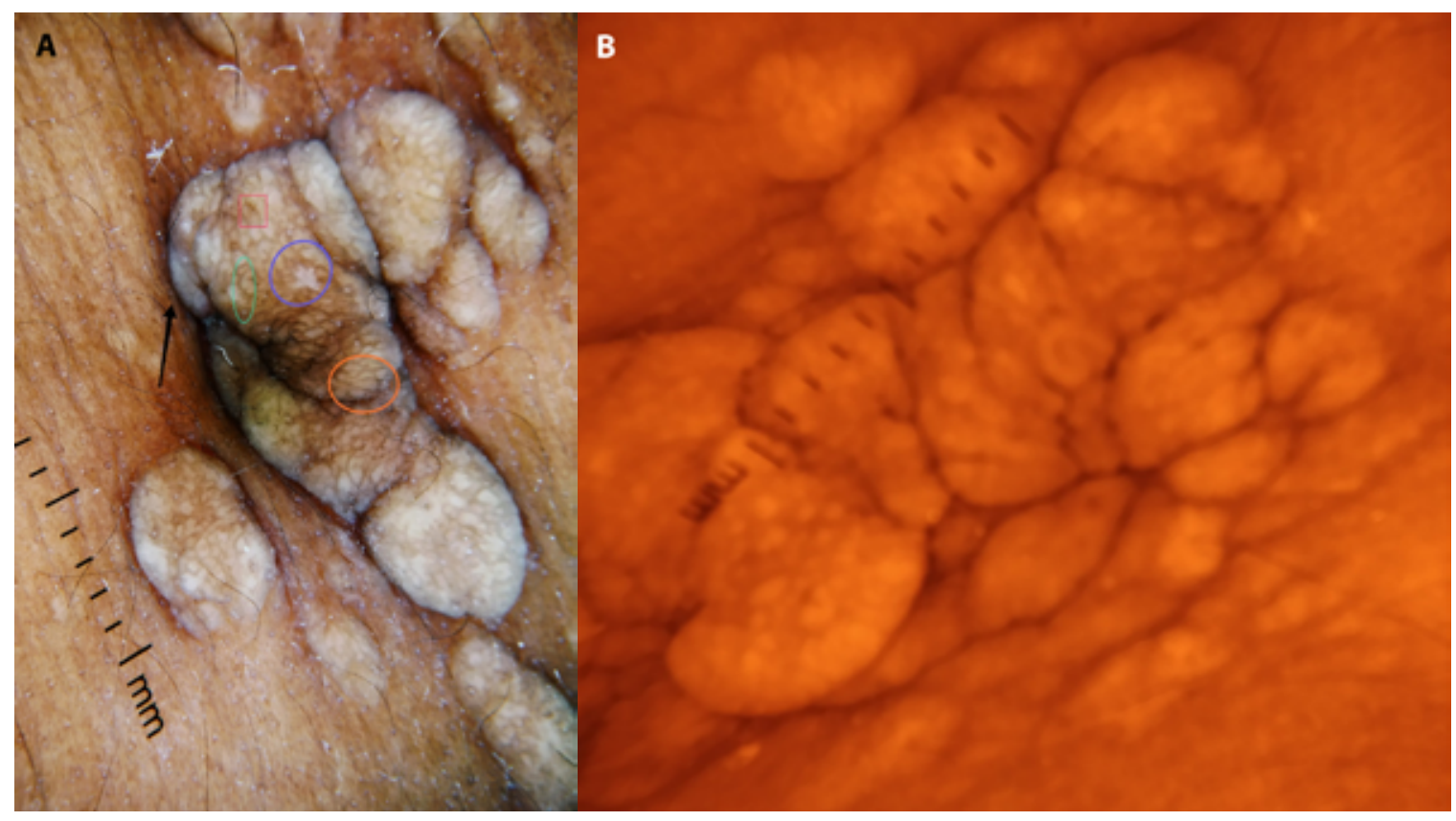

Figure 2. (A) Dermoscopy showing yellow structureless areas (orange circle), keratotic plugs in the sulci (red square), white structureless areas (blue circle), parallel line pattern (green circle), and a peripheral white homogenous area (black arrow). (B) Enhancement of structureless yellow areas on pigment-enhancing mode.

showed enhancement of the yellow structureless areas (dermal lipocytes) and white structureless areas (dermal collagen) which further favors the diagnosis of NLCS (Figure 2B). The cerebriform surface seen on dermoscopy represents the uneven surface formed by sulci and gyri, the yellow structureless areas represent dermal adipocytes, the presence of a regular pigment indicates the relative histological preservation of the normal rete ridges [2], and the white structureless areas represent the perifollicular fibrosis and thickened collagen in the dermis. Our findings are consistent with the dermoscopic features described previously by Vinay et al who described 5 features of NLCS: cerebriform appearance, web-like regular pigment network, rim showing a white veil, yellowish structureless areas, and comedo-like openings [2]. The differentials include lymphangioma circumscriptum, nevus sebaceous and neurofibromatosis.

\section{Conclusions}

Dermoscopy serves as a non-invasive tool in the diagnosis of NLCS and helps to differentiate it from other cutaneous conditions like lymphangioma circumscriptum, nevus sebaceous and neurofibromatosis.

\section{References}

1. Bhushan P, Thatte SS, Singh A. Nevus lipomatosus cutaneous superficialis: A report of two cases. Indian J Dermatol. 2016;61(1):123. DOI: 10.4103/0019-5154.174153. PMID: 26955147; PMCID: PMC4763661.

2. Vinay K, Sawatkar GU, Saikia UN, Kumaran MS. Dermatoscopic evaluation of three cases of nevus lipomatosus cutaneous superficialis. J Dermatol Venereol Leprol. 2017;83(3):383-386. DOI: 10.4103/ijdvl.IJDVL_677_16. PMID: 28366918. 